\title{
Reflexões semântico-lexicais do falar em Colíder-MT
}

\author{
Lexical-semantic reflections of the spoken language in Colider-MT
}

\author{
Maria José Basso MARQUES* \\ Universidade Estadual de Mato Grosso (UNEMAT) \\ Regina Uemoto Maciel MARTINS ${ }^{* *}$ \\ Universidade Estadual de Mato Grosso (UNEMAT)
}

\begin{abstract}
RESUMO: Este trabalho, de natureza léxico-semântica, trata da descrição e da reflexão das respostas dadas por 48 informantes, distribuídos em 6 pontos de inquérito no município de Colíder-MT, para as questões 15, 53, 54, 61, 70, 74, 78, 108, 128, 146, 148, 156 do Questionário Semântico-Lexical (ALiB, 2001). Essa localidade é fruto do movimento político no início do século XX, cuja finalidade era a ocupação territorial. Diante dos projetos para os incentivos e subsídios fiscais, a colonização se firmou e passou a receber um grande fluxo de famílias advindas de várias regiões do país, proporcionando uma diversidade cultural e linguística. O estudo orientou-se pelos princípios da Dialetologia, da Sociolinguística e da Geolinguística. A análise evidenciou que a realidade linguística local apresenta quadros multiformes do léxico, mostrando a influência de determinantes extralinguísticos, como a migração, a localização geográfica, a história e a cultura, revelando o mosaico que é a língua portuguesa.
\end{abstract}

PALAVRAS-CHAVE: Estudo semântico-lexical. Variantes. Questionário Semântico-Lexical. Colíder-MT.

ABSTRACT: This work, of a semantic- lexical nature, deals with the description and the reflection of the given answers by 48 informants, distributed in 6 survey points in Colíder-MT, for questions $15,53,54,61,70,74,78,108,128,146,148,156$ of the Lexical Semantic Questionnaire (ALiB in Portuguese, 2001). This locality is the result of the political movement in the early twentieth century, whose purpose was territorial occupation. Faced with projects for

\footnotetext{
* Mestra em Letras. Universidade do Estado de Mato Grosso. Mestrado Acadêmico - Programa de PósGraduação em Letras (PPGLetras). Sinop. E-mail: marialider@gmail.com

** Mestra em Letras. Universidade do Estado de Mato Grosso. Mestrado Acadêmico - Programa de PósGraduação em Letras (PPGLetras). Sinop. E-mail: reginauemoto@gmail.com
}

Revista Moara, n. 54, ago-dez 2019 ISSN: 0104-0944

Recebido em 12/08/2019

Avaliado em 30/10/2019 
tax incentives and subsidies, colonization was established and began to receive a large flow of families from various regions of the country, providing a cultural and linguistic diversity. The study was guided by the principles of Dialectology, Sociolinguistics and Geolinguistics. The analysis showed that the local linguistic reality presents lexical multiform frames, showing the influence of extralinguistic determinants, such as migration, geographical location, history and culture, revealing the mosaic of Portuguese language.

KEYWORDS: Lexical-semantic study. Variants. Lexical-Semantic Questionnaire. ColíderMT.

\section{Introdução}

Este trabalho utiliza como corpus um recorte dos dados geolinguísticos documentados para o Atlas Semântico-Lexical de Colíder-MT (ASeLCo, 2018) ${ }^{1}$ e faz uma reflexão das respostas coletadas e registradas. As análises recaem sobre as questões 15, 53, 54, 61, 70, 74, 78, 108, 128, 146, 148 e 156 do QSL do Atlas Linguístico do Brasil, (versão 2001).

Essas questões estão distribuídas entre as áreas Acidentes geográficos, Fenômenos atmosféricos, Astros e tempo, Atividades agropastoris, Fauna, Corpo humano, Ciclos da vida, Convívio e comportamento social, Religião e crenças e Jogos e diversões infantis. Foram verificadas as respostas fornecidas por 48 informantes, distribuídos em 6 pontos de inquérito, 5 na zona urbana de Colíder e 1 na zona rural (Comunidade Café Norte).

Visando a entender a motivação dessas respostas, este estudo buscou suporte teórico da Dialetologia e da Sociolinguística para compreender a variedade registrada. $\mathrm{O}$ questionário utilizado para a pesquisa do ASeLCo foi o QSL que contém 202 questões, distribuídas por 14 áreas semânticas, com denominações de emprego mais geral para duas grandes áreas Terra e Homem, as quais documentam a variação diatópica sem priorizar regionalismos, arcaísmos ou linguagens especiais de grupos. (MOTA, 2014).

\footnotetext{
1 Atlas Semântico-Lexical de Colíder-Mato Grosso, Dissertação de Mestrado, descreve e analisa os processos de variação linguística na constituição do léxico dos falantes no município de Colíder, traçando fotografias sociolinguísticas sob o aspecto semântico-lexical do(s) falar/falares dos migrantes e dos informantes nascidos nessa comunidade.
} 
Além disso, para Cardoso (2016), concluído um atlas linguístico, abrem-se portas as mais diversas para a investigação linguística, pois os dados cartografados fornecem usos correntes na área investigada, os quais podem ser vistos não apenas como retrato da língua naquele momento e naquela área, mas como indicadores de mudanças que se esboçam, de comportamentos linguísticos, de usos que se especificam conforme o tipo de falante, de interferências do léxico atreladas às transformações político-econômicas, entre outras.

Este artigo expõe, primeiramente, uma breve discussão teórica acerca das noções que fundamentam a análise dos dados para a elucidação da proposta. Em seguida, faz um breve histórico da localidade e apresenta a análise das lexias coletadas. A última seção destina-se às considerações finais do estudo.

\section{O léxico}

Um aspecto marcante que reflete a língua em relação à língua/cultura/sociedade é o léxico, ou seja, o conjunto de palavras de uma língua por meio do qual o homem nomeia a realidade que o cerca. Linguisticamente, "a palavra léxico designa o conjunto das unidades que formam a língua de uma comunidade, de uma atividade humana, de um locutor, etc.” (DUBOIS, 2006, p. 364).

Para Biderman (1998, p. 11), “o léxico de uma língua natural constitui uma forma de registrar o conhecimento do universo. Ao dar nomes aos seres e objetos, o homem os classifica simultaneamente. Foi esse processo de nomeação que gerou o léxico das línguas naturais”. Esse processo está indissoluvelmente associado à cultura com que se conjuga uma língua natural. Daí resultam as disparidades vocabulares que opõem, muitas vezes, variedades de uma mesma língua.

Outra questão importante pautada pela autora é a explosão do léxico nas modernas culturas e civilizações, gerando designadores de novos conceitos que se vão formando e criando vocábulos. As mudanças da contemporaneidade e a interação levam o homem a criar novas palavras em um processo incessante. E o léxico vai assumindo dimensões gigantescas, sendo praticamente impossível registrá-lo e descrevê-lo por meio de um dicionário. (BIDERMAN, 2006). 
Entende-se, assim, que o repertório lexical de uma língua revela a cultura e a classificação que o homem dá aos seres e objetos através da palavra. Então, a unidade lexical é o lugar de observação dos fatos, dos feitos e promove a possibilidade de o falante arquivar não só atividades extralinguísticas, mas também o saber linguístico de uma comunidade.

Como o falante arquiva, ele também emana seu conhecimento ao próximo e é nesta manifestação que os indivíduos expressam todo o vocabulário adquirido em suas origens, convivência e culturas. Assim, o estudo do léxico de uma comunidade busca a identidade revelando suas peculiaridades, e o idioleto de cada indivíduo.

Coseriu (1977) esclarece que cada sistema apresenta uma fisionomia particular, pela diversidade que se manifesta nas línguas, no sistema fonológico, no signo lexical e morfológico e no sistema semântico. Para o autor, a dificuldade maior em distinguir norma e sistema se encontra no campo lexical, não pela dificuldade inerente à distinção entre sistema e norma, mas pela enorme complexidade e infinita variedade das oposições que se estabelecem nesse campo devido ao estudo sistemático do vocabulário. Assim, o autor define:

La norma es la realización coletiva del sistema, que contiene el mismo y, además, los elementos funcionalmente "no-pertinentes" pero normales en el hablar de uma comunidade; el hablar (o, si quiere, habla) es la realización individual concreta de la norma, que contiene la norma misma y, además, la originalidad expressiva de los indivíduos hablantes (COSERIU, 1977, p. 58).

Nesse cenário, depreende-se que o sistema funciona como um conjunto de regras que permitem inovações sem prejuízo ao seu caráter formal, a norma é a realização coletiva do sistema e que recebe as inovações da fala e, de acordo com seu uso frequente, é fixada pela comunidade linguística, e a fala é a representação concreta do sistema e das normas.

Nesse sentido, esse estudo versará sobre a semântica lexical das lexias, que é a unidade do léxico constituída no momento da fala do locutor e que conforme Biderman (1996, p.44) “pode ser armazenada na memória do indivíduo, para que ele possa recuperar as palavras nesse tesouro vocabular quando delas precisar para se expressar ou se comunicar". 


\section{Breve panorama geossociolinguístico}

A natureza da língua é dinâmica e por isso se modifica continuamente no tempo. No entanto, é considerada por muitos como estática e permanente, pois as mudanças que ocorrem passam por um processo lento e parcial. Faraco explica que: “[...] as mudanças atingem sempre partes e não o todo da língua, o que significa que a história das línguas se vai fazendo num complexo jogo de mutação e permanência, reforçando aquela imagem antes estática do que dinâmica que os falantes têm de sua língua" (FARACO, 2006, p. 15).

Outra característica da língua é a sua heterogeneidade, pois é composta de variedades linguísticas provocadas por fatores temporais, sociais, culturais, geográficos e estilísticos. Para se compreender como se produz a relação entre as variedades linguísticas e os fatores extralinguísticos, a Dialetologia, que é a responsável por estudar essas variedades existentes e seus respectivos determinantes em uma mesma língua, trouxe grande contribuição. Cardoso (2010, p. 15) explica que “A Dialetologia [...] tem por tarefa identificar, descrever e situar os diferentes usos em que uma língua se diversifica, conforme a sua distribuição espacial, sociocultural e cronológica”.

Inicialmente, segundo Cardoso (2010), a Dialetologia era voltada para identificar e analisar as variedades geográficas (visão monodimensional), no entanto, no decorrer dos tempos, vem considerando outras dimensões dos fatos, incorporando ao confronto da variação diatópica a correlação com os fatores sociais, culturais e temporais (visão pluridimensional).

\footnotetext{
Os objetivos da Dialetologia visam (i) descrever, nos espaços geográficos recobertos por uma determinada língua ou por um conjunto de línguas, fatos característicos; (ii) qualificar, do ponto de vista social, as ocorrências registradas e; (iii) examiná-las na perspectiva do tempo a que estão submetidas (CARDOSO, 2016, p. 13).
}

Ainda na percepção de Cardoso (2016), o ponto de vista diatópico (espacial, geográfico), no início dos seus estudos, ocupava o maior foco da Dialetologia, pois os fenômenos linguísticos analisados adquiriam maior clareza e percepção nos ambientes 
geográficos, uma vez que o falante é inseparável do seu lugar nas suas formas de existir e ser.

No entanto, o estudo monodimensional, como se apresentava na Dialetologia, não proporcionava uma interpretação ampla da diversidade. Assim, a Sociolinguística veio complementar os estudos da variação linguística, ao oferecer a investigação dos aspectos que tratam da variedade sociocultural (diastrática) e tem como objeto de estudo a diversidade linguística, a qual ocorre devido a fatores sociais, tais como idade, sexo, grau de instrução, estilo, classe social e outros. Dessa forma, segundo Mollica (2010), cabe à Sociolinguística, averiguar o grau de estabilidade ou de mutabilidade da variação, diagnosticar as variáveis e prever seu comportamento regular e sistemático.

Segundo Alkmim (2001), foi no ano de 1964, em um congresso o qual ocorreu na Universidade da Califórnia, em Los Angeles, que William Bright e vários outros estudiosos discutiram a relação entre linguagem e sociedade e foi nesse contexto que o autor escreveu o texto introdutório "As dimensões da Sociolinguística" (1974) e propôs que essa ciência deveria “[...] demonstrar a covariação sistemática das variações linguística e social. Ou seja, relacionar as variações linguísticas observáveis em uma comunidade às diferenciações existentes na estrutura social desta mesma sociedade" (BRIGHT, 1974 apud ALKMIM, 2001, p. 28)

Alkmim (2001) ainda destaca que o objeto de estudo da Sociolinguística é a língua falada em seu contexto real de uso, o qual permite que o processo de interação verbal aconteça de maneira funcional, permitindo a comunicação. A autora explica que:

\footnotetext{
Uma comunidade de fala se caracteriza não pelo fato de se constituir por pessoas que falam do mesmo modo, mas por indivíduos que se relacionam, por meio de redes comunicativas diversas, e que orientam seu comportamento verbal por um mesmo conjunto de regras (ALKMIM, 2001, p. 31).
}

Vale ressaltar que, embora, no passado, estudiosos pensassem numa convergência entre a Dialetologia e a Sociolinguística, parece não ser consensual o posicionamento dos estudiosos acerca de seus espaços de atuação. Assim, temos Blanch (1978 apud SILVA, 2003), que contraria as formulações: Dialetologia como linguística diatópica e a Sociolinguística como linguística diastrática. Segundo ele, se a 
Dialetologia tem como finalidade geral o estudo das falas, deverá tratar tanto das suas variedades regionais como das sociais, tanto do eixo horizontal quanto do vertical.

Já Silva (2003) entende que a Dialetologia tem seu olhar voltado para as diversidades horizontais, centradas nas questões geográficas, regionais (diatópicas). Enquanto as questões verticais, focadas nas questões sociais (diastráticas) seriam de responsabilidade da Sociolinguística.

Assim, a autora traz para consideração e análise o seguinte quadro de resumo.

Quadro 1- Quadro comparativo - Dialetologia e Sociolinguística

\begin{tabular}{|c|c|}
\hline Dialetologia & Sociolinguística \\
\hline Estrutura-se no século XIX & Surge na década de 1960 \\
\hline Centra o seu interesse pela dialetologia regional. & $\begin{array}{l}\text { Centra seu interesse na variação luz das causas } \\
\text { sociais. }\end{array}$ \\
\hline $\begin{array}{l}\text { Identifica-se com a linguística diatópica, } \\
\text { horizontal. }\end{array}$ & Identifica-se com a linguística diastrática vertical. \\
\hline
\end{tabular}

Esse quadro permite fazer uma leitura distinta entre os dois ramos linguísticos. Percebe-se, assim, que independente do posicionamento dos diferentes teóricos sobre a área de atuação de cada um, os dois trouxeram contribuições valiosas para os estudos da língua em geral.

\section{Colíder: breve histórico}




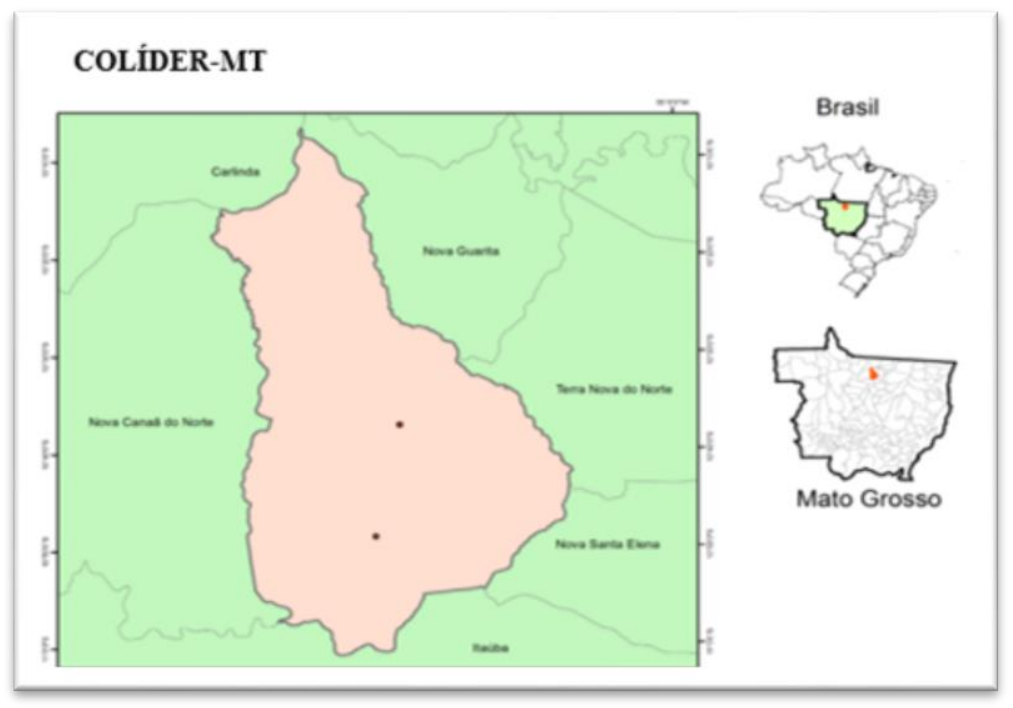

Fonte: elaborado por Holzschuhem (2018)

A colonização do norte mato-grossense, a partir da década de 1970, foi impulsionada pela política governamental de ocupação da Amazônia. Conforme SCHAEFER (1986, p. 203), “formou-se um movimento constituído por uma população rural em busca de terra no Estado, expulsa do Sul do país e conduzida pelos colonizadores modernos".

Nesse mesmo ano, Raimundo Costa filho resolveu arriscar "grandes jogadas", comprando terras e vendendo para colonos do Sul e com dinheiro suficiente constituiu uma firma de colonização, a COLIDER (Colonização, Industrialização e Desenvolvimento Rural). O próximo passo foi seguir no encalço da abertura da BR 163, estabelecendo-se na altura do $\mathrm{km} 620$, cerca de $40 \mathrm{~km}$ à esquerda da abertura da rodovia, onde construiu a sede da colonizadora.

Para uns, Raimundo loteou uma área de 24 mil hectares, para outros, transformou essa área em 330 mil hectares. No ano de 1974, a Colíder S/A intensificou a publicidade no Paraná, anunciando as excelências das terras da região, do clima, facilidades de pagamentos, propaganda que proporcionou a vinda de centenas de famílias, entre elas ex-posseiros, volantes, pequenos agricultores, que foram chegando e se instalando ao redor da sede e formando o atual município de Colíder. 
Nos últimos 40 anos, transformações se intensificaram geradas, primeiramente, pela busca do ouro, e, posteriormente, pelo destaque com agroindústrias de cadeia pecuária, como a vinda de um frigorífico, curtume, laticínios, indústria de biocombustível e, mais recentemente, a construção da usina hidrelétrica, gerando empregos e proporcionando mudanças socioeconômicas. Nesse ínterim, a migração não cessou e, de acordo com a estimava do IBGE de 2017, esta localidade conta com 32.298 habitantes.

Nesse contexto, culturas se mesclaram atuando com a língua, proporcionando variedades linguísticas que são o resultado do entrelaçamento das experiências históricas e socioculturais de grupos advindos de vários estados do país. Conforme Cuba e Isquerdo, (2009, p. 146), as variações linguísticas estão relacionadas "a fatores que podem ser traduzidos na relação entre língua e espaço físico, no caso as variações geográficas que, por sua vez, estão constantemente condicionadas a fatores sociais, culturais e históricos".

\section{Análise dos dados}

A pesquisa contemplou 5 pontos na zona urbana e 1 na zona rural, representado pela Comunidade Café Norte, do município de Colíder. O estabelecimento dos lugares levou em consideração a história local, que é de migração, a densidade demográfica e a distribuição espacial desses habitantes, nas localizações de inquérito, as quais estão assim organizadas: ponto 1- Setor Oeste (4.210 hab.), ponto 2 - Setor Sul (3.860 hab.), ponto 3 - Centro (2.245 hab.), ponto 4 - Setor Leste (3.147 hab.), ponto 5 - Setor Norte (1542 hab.) e ponto 6 - Comunidade Café Norte (200 hab.).

A averiguação foi realizada in loco junto a 48 informantes, 8 por ponto, os quais atendem a 03 parâmetros: diageracional: duas faixas etárias - a primeira faixa, de 18 a 40 anos, nascidos no local, se não nascidos, que tenham vivido no mínimo 30 anos na localidade, e a segunda faixa, acima de 50 anos de idade com permanência de pelo menos 30 anos.

Para o parâmetro diagenérico, distribuem-se igualmente pelos dois sexos, 24 homens e 24 mulheres. E, para a variável escolaridade, definiram-se duas, a primeira, 
analfabetos ou ter completado ou não o Ensino Fundamental, e, a segunda, ter nível Médio até o Universitário.

Foram aplicadas as 202 questões do Questionário Semântico-Lexical do ALiB, versão 2001, contudo o recorte para tecermos comentários, de caráter semântico-lexical, recaem sobre as lexias diferentes das possibilidades de respostas dos temas/conceitos, já registrados, também, em outros atlas e que se estão como guia para o pesquisador no QSL do ALiB. As questões fazem parte de 10 áreas semânticas, e as reflexões foram realizadas com base em quatro dicionários, Bluteau (1712-1728), Ferreira (1999), Houaiss (2011) e Michaelis Digital (2015) e de acordo com as variáveis extralinguísticas: diatópica e social. As respostas referem-se às seguintes questões:

* 15. Durante uma chuva podem cair bolinhas de gelo. Como chamam essa chuva?

* 53. Como se chama as duas partes em que a pessoa segura para empurrar o (cf. item 52)?

54. ... a armação de madeira, em forma de forquilha (mímica), que se coloca no pescoço de animais (porco, terneiro/bezerro, carneiro, vaca) para não atravessarem a cerca?

* 61. ... homem que é contratado para trabalhar na roça de outro, que recebe por dia de trabalho?

* 70.... um cachorro de rabo cortado?

* 74. ... o cabelo comprido na traseira do cavalo?

* 78. ... o boi sem (cf. item 77)?

* 108. ... esta parte aqui? (Apontar)

* 128. Quando a mãe não tem leite e outra mulher amamenta a criança, como chamam essa mulher?

* 146. ... o resto do cigarro que se joga fora?

* 148. O que algumas pessoas dizem já ter visto, à noite, em cemitérios ou em casas, que se diz que é do outro mundo?

* 156. ... as coisinhas redondas de vidro com que os meninos gostam de brincar? 
O quadro, a seguir, expõe o comparativo entre conceito/tema apresentado no início das perguntas do QSL do ALiB e as lexias registradas, através da pesquisa, para o ASeLCo, àquelas que obtiveram o maior número de ocorrências.

Para a leitura dos dados tem-se a seguinte disposição: a primeira coluna expõe o número da questão e a(s) possibilidades de variantes já registradas em outros Atlas e que vem como um guia para o pesquisador no QSL do ALiB; a segunda, as lexias documentadas e que são distintas dessas. A terceira expõe os parâmetros sociais, sendo apresentada a variável com maior concentração entre os pares. Dessa forma, tem-se, $\mathrm{M}$ para masculino, F para feminino, FE1- primeira faixa etária, FE2- segunda faixa etária, F - escolaridade de nível de fundamental e $\mathrm{S}$ - escolaridade de nível superior. Na sequência, a indicação do número de pontos em que foram registradas as lexias, a ocorrência e frequência e o item que se constitui em norma.

Vale destacar que são considerados norma os itens lexicais que obtiveram distribuição regular, ou seja, foram utilizados por sujeitos em todos os pontos de inquérito e apresentaram frequência de uso acima das demais, isto é, atingiram acima de $50 \%$, representando a norma lexical em Colíder. Ressalta-se que a norma é entendida aqui como "[...] padrão grupal de uso. É norma tudo o que é de uso comum e corrente numa dada comunidade linguística”. (CRISTIANINI, 2007, p. 108). 
Quadro 2 - Lexias registradas no ASeLCo diferentes daquelas que estão no índice do QSL

do ALiB

\begin{tabular}{|c|c|c|c|c|c|c|}
\hline AliB & Lexias /AS eLCo & Variáveis & Pontos & Ocorrências & $\mathbf{F}$ & \\
\hline \multicolumn{7}{|c|}{ I- A cidentes Geográficos } \\
\hline 15- chuva de pedra & granizo/granito & F-FE1-S & 6 & 29 & $60 \%$ & norma \\
\hline \multicolumn{7}{|c|}{ IV-A tividades Agropastoris } \\
\hline 53-hastes do carrinho de mão & cabo & M-FE2-S/F & 6 & 26 & $54 \%$ & norma \\
\hline 54-forquilha/cang alha & canga & M-FE2-S & 6 & 27 & $56 \%$ & norma \\
\hline 61-trabalhador enxada & diarista & $\mathrm{M} / \mathrm{F}-\mathrm{FE} 2-\mathrm{S} / \mathrm{F}$ & 6 & 28 & $58 \%$ & norma \\
\hline \multicolumn{7}{|c|}{ V-Fauna } \\
\hline 70 - cotó & pitoco & F-FE1-F & 6 & 32 & $67 \%$ & norma \\
\hline 74- crina da cauda & rabo & M-FE1S/F & 6 & 45 & $94 \%$ & norma \\
\hline 78-boi sem chifre & mocho & F-FE2-S & 6 & 43 & $90 \%$ & norma \\
\hline \multicolumn{7}{|c|}{ VI-Corpo humano } \\
\hline 108- axila & subaco/suvaco & F-FE2-S/F & 6 & 39 & $81 \%$ & norma \\
\hline \multicolumn{7}{|c|}{ VII- Ciclos da vida } \\
\hline 128-ama de leite & mãe de leite & M-FE2-F & 6 & 37 & $77 \%$ & norma \\
\hline \multicolumn{7}{|c|}{ VIII- Convívio e comportamento social } \\
\hline 146- toco de cig arro & bituca & M-FE1-F & 6 & 45 & $94 \%$ & norma \\
\hline \multicolumn{7}{|c|}{ IX-Religião e crenças } \\
\hline 148-fantasma & assombração & M-FE2-F & 6 & 28 & $58 \%$ & norma \\
\hline \multicolumn{7}{|c|}{$\mathrm{X}$ - Jogos e diversões in fantis } \\
\hline 156- bolinha de gude & burca/burquinha & F-FE1-S & 6 & 24 & $50 \%$ & norma \\
\hline
\end{tabular}

Fonte: Atlas semântico-lexical de Colíder - MT (MARQUES, 2018).

De acordo com os registros elencados, dos itens norma, sobressaem àqueles que alcançaram frequência igual ou superior a 90\%, que são: rabo e mocho, da área semântica Fauna, e bituca, da área Convívio e Comportamento Social.

O termo rabo (questão 74) conforme as acepções dos lexicógrafos, Bluteau (1712-1728), Ferreira (1999) e Michaelis (2015), é entendido como: (i) o prolongamento da coluna vertebral de certos mamíferos, (ii) cauda. Para Houaiss (2011), é um conjunto de nádegas e/ou ânus. Já a unidade léxica crina é definida como "pelo comprido, firme e flexível, que o cavalo e outros animais têm no alto da cabeça, no pescoço e na cauda" (MICHAELIS, 2015).

Diante desse contexto semântico, o que se percebe é que os entrevistados, ao utilizarem a palavra rabo, fazem proximidade de ideias, associação do conjunto, pelos e rabo, para denominarem a parte posterior do cavalo com um só vocábulo, ou seja, realizam, talvez inconscientemente, um processo metonímico, troca de um termo por outro de forma similar.

Já mocho (questão 78), conforme Michaelis Digital (2015), advém do espanhol e significa estar desprovido de chifres ou que teve os chifres aparados. Segundo Costa e Isquerdo (2013), no artigo intitulado Espanholismos no Léxico do Brasil Central: 
contribuições do projeto $A L i B^{2}$, a primazia espanhola vigorava no Brasil Central, por meio do Tratado de Tordesilhas (1494-1750), em que as terras de Mato Grosso do Sul, Mato Grosso e parte de Goiás integravam, até 1750, a Província do Paraguai, quando mudaram para o domínio de Portugal, conforme um novo acordo de limites, o Tratado de Madri, firmado entre Espanha e Portugal.

Esse fato histórico e várias obras dicionarizadas consultadas pelas autoras permitiram-nas afirmar que mocho, vocabulário encontrado no falar dessa região, é de base castelhana. Dessa forma, é possível inferir que este item talvez seja uma influência do espanholismo compartilhado entre os mato-grossenses, uma vez que, no passado, Mato Grosso teve intervenção de cidadãos da América espanhola na cultura.

Para o termo bituca (questão 146), obteve 94\% de respostas com uso frequente na fala de homens e mulheres das duas faixas etárias e escolaridades. Vale destacar que, das 45 respostas, 14 foram dadas por migrantes do Paraná e 12 por migrantes de São Paulo. Esse contexto nos leva a acreditar que a língua portuguesa local apresenta particularidades, ora se identificando com o falar dos habitantes do estado Paraná, ora com os de São Paulo, as quais, possivelmente, são heranças linguísticas adquiridas através do contato linguístico entre os migrantes durante o processo de colonização que compõe o Norte de Mato Grosso.

Já a análise semântica, em consulta a 4 dicionários, encontramos significado em apenas 2, Ferreira (1999), que, ao verificar a primeira entrada, informa outro vocábulo para identificar o significado, que no caso sugere, V. guimba. Já no segundo, Michaelis Digital (2015), a designação compreende o nome dado à parte que sobra após consumir o cigarro. Entende-se, então, que os informantes utilizam a variante bituca como sinônimo ao item toco de cigarro.

Para granizo/granito (questão 15), conforme as acepções dicionarizadas em Bluteau (1728), observa-se que houve uma mudança na grafia, de /s/ para /z/, do item granizo, o qual aparece grafado como graniso. Já nas respostas registradas para o ASeLCo, têm-se variação fonológica, de /z/ para /t/, granito. Dessa forma, poderíamos

\footnotetext{
${ }^{2}$ Espanholismos no léxico do Brasil central: contribuições do projeto ALiB o que nos dizem os dados do Atlas Linguístico do Brasil/ Centro Oeste. O trabalho discute a presença de unidades léxicas de base espanhola no falar da região Centro-Oeste do Brasil documentadas pelo Projeto Atlas Linguístico do Brasil. [...] evidenciaram-se, nos dados empíricos, traços da influência espanhola na região, por meio do uso de espanholismos para designar elementos da fauna.
} 
pensar numa "mudança de pronúncia, já que a escrita é utilizada para representar os sons, ou talvez, no primeiro caso, uma mudança ortográfica” (FIORIN, 2015, p. 144).

Na pesquisa realizada por Romano (2012), para o Atlas Geossociolinguístico de Londrina: um estudo em tempo real e aparente, o autor confirma que o uso da lexia chuva de granizo e suas variantes é uma forma inovadora falada atualmente no Norte de Londrina, região de colonização mais recente em contraponto à lexia chuva de pedra, de uso no Sul do Paraná, por informantes que apresentam um falar conservador. Por analogia ao contexto de migração dessa região, podemos deduzir que Colíder recebeu, para a constituição do seu léxico, essa forma inovadora para o conceito da pergunta 15 .

A lexia cabo (questão 53), usada para denominar a haste do carrinho de mão, é um vocábulo que se concentra na fala dos homens. Em Colíder, a profissão de pedreiro é muito comum e uma das principais ferramentas do trabalho é a carriola, como é denominada nesta localidade. Além disso, essa profissão é executada, principalmente, pelos homens. Provavelmente, esse contexto seja o condicionador da concentração dessa lexia na fala masculina.

A forma canga (questão 54), que faz parte da área semântica Atividades agropastoris, é mais produtiva na fala dos homens mais velhos, o que nos leva a considerar que esses falantes têm mais contato com as atividades relacionadas ao cuidado com animais, uma vez que as mulheres ficam responsáveis pelas atividades domésticas.

Nesse sentido, esclarece Philippsen (2013) que o trato com atividades no meio rural não é uma prática comum, uma vez que a pecuária tomou o espaço da agricultura somada aos eventos da modernidade e das novas tecnologias, distanciando o jovem do campo. Outro fator elencado pela autora se deve ao fato de as atividades rurais estarem se tornando obsoletas no Norte de Mato Grosso, devido ao processo de ajustamento à vida urbana, uma vez que o espaço geográfico, encontrado pelos migrantes em 1970, era mata fechada e, aos poucos, as glebas e vilas se tornaram cidades, como é o caso dessa localidade.

Para a questão 61, diarista, uma busca por três lexicógrafos, Ferreira (1999), Houaiss (2011) e Michaelis (2015), encontra-se o sentido de trabalhador que ganha por diária realizada ou por dia de trabalho. Em Colíder é comum contratar pessoas para trabalhar "por dia" na "lida do campo". Esse trabalhador "diário" é comum, também, 
em datas festivas, principalmente no fim do ano, quando aumentam as vendas no comércio e os comerciantes precisam de pessoas para trabalharem apenas naquele período de grande demanda, contratando os "diaristas". Então, infere-se que, para os falantes colidenses, tanto o trabalhador que "trabalha em roça alheia por dia", quanto aquele que faz trabalho apenas em temporadas festivas, recebe a mesma denominação, diarista.

Quanto à lexia pitoco (questão 70) é usada por informantes de ambas as faixas etárias. Em Michaelis Digital (2015) registra-se que esse termo é de uso coloquial e significa qualquer objeto comprido a que falta um pedaço. Essa lexia também foi registrada por Aguilera (1994) na fala paranaense para denominar um animal de rabo cortado (cf. Carta 121, p.143). Provavelmente, este vocábulo seja mais uma contribuição paranaense, o que sugere a conservação desse item tanto pelos sujeitos mais velhos quanto pelos mais novos.

Já a lexia subaco (questão 108) e sua variante fonológica suvaco são recorrentes em todos os pontos de inquérito. Quanto à correlação entre variação linguística e o fator gênero/sexo, constatamos que a variante subaco é mais frequente entre os homens e informantes com nível fundamental. Esse dado sugere que a baixa escolarização seja o fator motivador desse processo fonético conhecido como betacismo, que, conforme consta no Dicionário de Termos Linguísticos (Associação Portuguesa de Linguística, s/d, p. 62), "é a inexistência de oposição fonológica entre os fonemas /b/ e /v/. Nas zonas de betacismo existe um único fonema /b/, com duas realizações contextuais: /b/ fricativo em posição intervocálica e /b/ verdadeiramente oclusivo, sem fricatização nos restantes contextos".

O único item lexical que não encontramos acepções nos dicionários pesquisados foi, da área Ciclos da Vida, mãe de leite (questão 128), o que confere o uso coloquial do falante. Dessa forma, buscamos o significado do item ama-de-leite. Ferreira (1999) assim conceitua essa entrada "[Do lat. hisp. Infantil amma] S. f. 1. ama-de-leite. 2. V. ama-seca. 3. A dona da casa em relação aos criados. 4. Governanta. (1). 5. Criada de companhia; aia. 6. Bras. N. E. Criada em geral”.

Como se percebe, a entrada ama-de-leite traz diversas acepções as quais contribuem para compreender que, para os informantes do ASeLCo, ao utilizarem a lexia mãe e seu caracterizador de leite, como resposta para a questão 128 , interpretam 
que a mulher que doa seu leite cumpre apenas o papel de amamentar a criança, sem exercer outros encargos, como ocorre com a ama.

Para a variante assombração (148), fica evidenciada uma manifestação de variação diageracional e diassexual, pois a incidência de respostas para essa forma foi maior na fala de entrevistados masculinos da segunda faixa etária. Talvez isso se explique pelo fato de o homem, nesta sociedade, mostrar-se mais envolvido com as atividades do campo, onde há uma tendência à conservação linguística, mítica e religiosa.

Sobre o aspecto semântico, conforme Ferreira (1999), Houaiss (2011) e Michaelis Digital (2015), comprovamos que o conceito de assombração caracteriza o mesmo sentido dado a fantasma, ou seja, algo imaterial que provoca medo, pânico, por ser considerado extranatural.

Para o campo Jogos e diversões infantis, a forma burca/burquinha (156), apresentou maior uso por informantes da primeira faixa etária e por mulheres. Quanto ao sentido em Michaelis Digital (2015), encontramos o item búraca como sinônimo de gude. Para o mesmo lexicógrafo, búraca é um regionalismo do Estado do Rio de Janeiro e tem como variante a lexia búrica. Em Ferreira (1999, p. 342) há apenas entrada para búrica: "S. f. Bras. RJ V. gude". Tal definição nos leva a hipotetizar que burca/burquinha possam ser variantes fonológicas do item lexical búraca.

Ainda sobre esse item, ao se observar o estudo de Romano e Aguilera (2014), em Padrões de variação lexical na região sul a partir dos dados do Projeto Atlas Linguístico do Brasil, o qual discute a distribuição diatópica de variantes lexicais para a questão 156- Como se chamam as coisinhas redondas de vidro com que os meninos gostam de brincar?, pode-se verificar, conforme afirmam os autores, que a variante burca/buquinha é uma forma lexical típica do Sul do Paraná. Eles acrescentam:

\footnotetext{
A segunda área que configura outro padrão lexical na região Sul apresenta-se sob a isoléxica da variante burquinha. No ALERS, essa área abrange o centro, o sudeste e o litoral paranaense, ao passo que, nos dados do ALiB, restringe-se, exclusivamente, ao norte e noroeste do Paraná (ROMANO; AGUILERA, 2014, p. 583).
}

Assim, diante das informações acima mencionadas, infere-se, mais uma vez, que as influências regionais, trazidas pela migração paranaense, propiciaram a formação do 
dialeto local, com traços que são impressos pela cultura daqueles que fazem uso da língua, evidenciados pelo processo de ocupação e povoamento. Por fim, essas reflexões indicam que os dados examinados neste trabalho dão mostras da influência de determinantes extralinguísticos, como a migração, a localização geográfica, a história, a cultura, os aspectos diageracionais e diassexuais.

Esses fatores contribuem para particularizar o repertório lexical em uso por esta comunidade, uma vez que o estudo da língua não se desvincula da dimensão históricosocial, pois "é no âmbito de um grupo social que a norma se instaura, é disseminada ou fica confinada a determinados espaços geográficos, dependendo das características socioculturais desse grupo" (ISQUERDO, 2006, p. 22).

\section{Considerações finais}

A partir do corpus analisado, em termos de uso da língua, ficou evidente que o acervo lexical de Colíder apresenta semelhanças e divergências, não podendo, portanto, ser classificado como uma área linguística homogênea, ocasionando diferença no repertório linguístico ou entre os falares dos referidos pontos, mostrando o mosaico que é a língua portuguesa.

Busse (2009) acentua que o espaço areal, como contexto para a investigação da fala, apresenta quadros multiformes da realidade linguística e constitui verdadeiros documentos do registro dos elementos que se unem à história, à cultura, aos percursos, aos trajetos no espaço e aos contatos entre as diferentes culturas.

Dessa forma, depreende-se que as descrições e reflexões apresentadas até aqui expõem que o local pesquisado constitui um vasto campo para as investigações dialetológica e sociolinguística e que os sentidos dados a esse léxico são produzidos de acordo com o contexto social, devido à história de migração e seu processo de povoamento.

\section{REFERÊNCIAS}


ALKMIM, Tânia Maria. Sociolinguística. In: MUSSALIM, Fernanda, BENTES, Anna Christina (orgs.). Introdução à Linguística: domínios e fronteiras. Vol. 1. São Paulo: Cortez, 2001. p. 21-47.

ASSOCIAÇÃO PORTUGUESA DE LINGUÍSTICA. Instituto de linguística Teórica Computacional. Dicionário de Termos Linguísticos. Lisboa. COSMOS. v. 1.

BIDERMAN, Maria Tereza Camargo. Léxico e vocabulário fundamental. Alfa Revista de Linguística. São Paulo, v. 40, 27- 46. 1996. Disponível em: https://periodicos.fclar.unesp.br> Acesso em 23 dez. 2019.

A face quantitativa da linguagem: um dicionário de frequência do português. Alfa Revista de Linguística. São Paulo, v. 42 (n. esp.), 161-181. 1998. Disponível em: https://periodicos.fclar.unesp.br/alfa/article/view/4049 > Acesso: em ago. 2019.

O conhecimento, a terminologia e o dicionário. Cienc. Cult. [online]. 2006, vol.58, n.2 [cited 2019-08-03], pp.35-37. Available from: $<$ http://cienciaecultura.bvs.br/scielo.php?script=sci_arttext\&pid=S0009$67252006000200014 \& \operatorname{lng}=e n \& n r m=$ iso $>$. ISSN 2317-6660.

BUSSE, Sanimar. Atlas linguístico-etnográfico da região Oeste do Paraná/ALERO: uma descrição preliminar do movimento diatópico e diastrático da fala. SIGNUM: Estudos da Linguagem. Londrina, v.12, n.1, 2009. p.123-144.

BLUTEAU, Raphael. Vocabulario portuguez \& latino: aulico, anatomico, architectonico. Coimbra: Collegio das Artes da Companhia de Jesus, 1712 - 1728. v. 8.. Disponível em: http://dicionarios.bbm.usp.br/pt-br/dicionario/edicao/1> Acesso em: ago. de 2019.

CARDOSO, Suzana Alice Marcelino da Silva. A dialectologia no Brasil: Perspectivas. Delta. vol. 15. $\mathrm{N}^{\mathrm{o}}$ Especial. 1999. p. 233-255. Disponível em http://www.scielo.br/scielo.php?pid=S010244501999000300010\&script=sci_abstract\&tlng=pt $>$ Acesso em out 2016.

A história do Atlas Linguístico do Brasil. In: CARDOSO, Suzana Alice Marcelino da Silva. et al. Atlas Linguístico do Brasil: volume 1: Londrina. Eduel, 2014. p. 17-29.

Geolinguística: tradição e modernidade. São Paulo: Parábola Editorial, 2010. P. 15-26.

Revista Moara, n. 54, ago-dez 2019 ISSN: 0104-0944

Recebido em 12/08/2019

Avaliado em 30/10/2019 
Dialetologia. In: MOLLICA, Maria Cecília, FERRAREZI JUNIOR, Celso

(orgs.). Sociolinguística, sociolinguísticas: uma introdução. São Paulo: Editora Contexto, 2016. p. 13-22.

COMITÊ CIENTÍFICO DO PROJETO ALIB. Atlas Linguístico do Brasil:

Questionário. 2001. Londrina: Ed. UEL. Disponível em: https://alib.ufba.br/sites/alib.ufba.br/files/questionario_alib.pdf > Acesso em: 29 mar. 2019.

COSERIU. Eugenio. Lecturas de sociolinguiística. Madrid. 1977. Disponível em: http://www.romling.uni-tuebingen.de/coseriu/cospubli.html> Acesso em: ago. de 2019.

COSTA, Daniela de Souza Silva ; ISQUERDO, Aparecida Negri. Espanholismo no léxico do Brasil Central: contribuições do projeto ALiB. ALFA Revista de Linguística. Florianópolis, v.50, n.2, 2013. p. 133-145. Disponível em: https://periodicos.fclar.unesp.br/alfa/article/view/1408/1109> Acesso em: 29 de mar. de 2018.

CRISTIANINI, Adriana Cristina. Atlas semântico-lexical da região do grande ABC. USP. São Paulo, 2007. Disponível em: http://www.teses.usp.br/teses/disponiveis/8/8139/tde-28012008-115533/pt-br.php Acesso em: 25 de nov. de 2017.

CUBA, Marigilda Antônio; ISQUERDO, Aparecida Negri. Léxico e história social: um estudo da variante lexical neve no Atlas Linguístico da mesorregião sudeste de Mato Grosso. SIGNUM: Est. Ling. Londrina, v.12, n.1, 2009. p.145-162. Disponível em: http://www.uel.br/revistas/uel/index.php/signum/issue/view/347. Acesso em 04 de ago. de 2019.

DUBOIS. Jean. et al. Dicionário de linguística. São Paulo. Cultrix. 2006.

FARACO, Carlos Alberto. Linguística histórica: uma introdução ao estudo da história das línguas. São Paulo: Parábola Editorial, 2006. p. 14-43.

FERREIRA, Aurélio Buarque de Holanda. Novo Aurélio sec. XXI. Rio de Janeiro. Nova Fronteira, 1999.

FIORIN. José Luiz. (org.). Introdução à Linguística: I. objetos teóricos. 6. ed. São Paulo. Contexto, 2015.

HOUAISS. Dicionário Conciso. São Paulo: Moderna, 2011.

Revista Moara, n. 54, ago-dez 2019 ISSN: 0104-0944

Recebido em 12/08/2019

Avaliado em 30/10/2019 
INSTITUTO BRASILEIRO DE GEOGRAFIA E ESTATÍTICA. População estimada: IBGE, Diretoria de Pesquisas, Coordenação de População e Indicadores Sociais, Estimativas da população residente com data de referência 1o de julho de 2017. Disponível em https://cidades.ibge.gov.br/brasil/mt/colider/panorama> Acesso em ago. de 2019.

ISQUERDO, Aparecida Negri. Achegas para a discussão do conceito de regionalismos no português do Brasil. São Paulo. Alfa Revista de Linguística. v. 50, n. 2, p. 9-24. 2006. Disponível em: https://periodicos.fclar.unesp.br/alfa/article/view/1408> Acesso em: ago. 2019.

MARQUES, Maria José Basso. Atlas semântico-lexical de Colíder- Mato Grosso. Sinop 2018. 396 f. Dissertação. (Mestrado em Letras, Universidade Estadual de Mato Grosso, Sinop). Disponível em: http://portal.unemat.br/?pg=site\&i=ppgletrassinop\&m=dissertacoes\&c=turma-1 Acesso em: 01 de nov. de 2018.

MICHAELIS. Dicionário Brasileiro da Língua Portuguesa. Melhoramentos. 2015. Disponível em: http://michaelis.uol.com.br/. Acessado em ago. de 2019.

MOLLICA, Maria Cecília, BRAGA Maria Luiza. (orgs). Introdução à sociolinguística: o tratamento da variação. $4^{\text {a }}$.ed. São Paulo: Contexto, 2010.

MOTA, Jacyra Andrade. Percursos metodológicos: questionário e Informantes. In. Cardoso, Suzana Alice Marcelino da Silva et al. Atlas Linguístico do Brasil: volume 1: Londrina. Eduel, 2014. P. 79-93.

PHILIPPSEN, Neusa Inês. A constituição do léxico norte mato-grossense na perspectiva geolinguística: Abordagens Sócio-Semântico-Lexicais. São Paulo, 2013. Disponível em: http://www.teses.usp.br/teses/disponiveis/8/8142/tde-13092013125309/en.php> Acesso em: mar.2016.

ROMANO, Valter Pereira. Atlas geossolinguístico de Londrina: Um estudo em tempo real e tempo aparente. Londrina. 2012. Disponível em: https://alib.ufba.br/atlas-geossociolinguistico-de-londrina-agelo > Acesso em ago. 2019.

ROMANO, Valter Pereira; AGUILERA, Vanderci de Andrade. Padrões de variação lexical na região sul a partir dos dados do Projeto Atlas Linguístico do Brasil. Revista de Estudos Linguísticos. vol. 43 nº1.São Paulo. 2014. p.575-587. Disponível em: https://revistas.gel.org.br/estudos-linguisticos/article/view/460> Acesso em 08 de mar. de 2018. 
SCHAEFER, José Renato. As migrações rurais e implicações pastorais: Um estudo das migrações campo-campo do sul do país em direção ao norte de Mato Grosso. São Paulo. Loyola. 1986. p. 67-74.

SILVA, Maria. Emília. Barcellos da. Os estudos dialetológicos e o seu compromisso com o ensino. Cadernos da ABF. Vol. II, nº 01. Rio de Janeiro: Iletras UERJ, 2003. Disponível em: http://www.filologia.org.br/abf/volume2/numero1 /06.htm. Acesso em 02 ago. 2019. 